\title{
TLC Determination of Marmesin, a Biologically Active Marker from Feronia Limonia L.
}

\author{
Mahendra Jain*, Ashish Trivedi, S.H.Mishra
}

Herbal Drug Technology Laboratory, Pharmacy Department, Faculty of Technology and Engineering, The M. S. University of Baroda, Kalabhavan, Vadodara, Gujarat, India.

Email: *mjainms@gmail.com

Received August $9^{\text {th }}, 2010$; revised August 24 ${ }^{\text {th }}, 2010$; accepted September $6^{\text {th }}, 2010$

\begin{abstract}
Feronia limonia Linn. (Rutaceae) have gained traditional therapeutic importance owing to their high essential oil and coumarins content. Marmesin, a furanocoumarin was identified by TLC and isolated by column chromatography and further purified by Preparative TLC. Presently, there is no appropriate TLC based method available for standardization of F. limonia. A simple, sensitive and accurate high performance thin layer chromatographic (HPTLC) method has been developed for the estimation of marmesin in the methanolic extract of stem bark of Feronia limonia. HPTLC was performed on precoated silica gel $60 F_{254}$ aluminium plates $(20 \mathrm{~cm} \times 20 \mathrm{~cm})$ with Chloroform: Methanol (9.5:0.5), as mobile phase. Quantitative evaluation of the plate was performed in the absorption-reflection mode at $338 \mathrm{~nm}$. The calibration curve was linear in the concentration range of $20-100 \mathrm{ng} \mathrm{spot}^{-1}$. The method was validated for precision, repeatability and accuracy. The technique has been applied, for the first time, for the estimation of marmesin. The proposed method was found to be robust, precise, and accurate, it therefore holds potential for detection, monitoring and quantification of marmesin in Feronia limonia and its related formulation.
\end{abstract}

Keywords: Marmesin, Feronia Limonia, HPTLC

\section{Introduction}

Standardization and characterization of herbal drugs is a topic of continuous scientific interest in the herbal drug industry [1]. With the advent of modern chromatographic systems there is an ever increasing intent to produce and develop easy, rapid, convenient and cost effective methods for standardization of herbal drugs based on their phytoconstituents. This requirement is fulfilled by thin layer chromatography (TLC) [2,3]. Feronia limonia is (family Rutaceae, subfamily Aurantioideae), commonly known as wood-apple, belongs to the tribe Citreae and subtribe Balsamocitrinae[4] which is widely distributed in dry warm regions of India, Bangladesh, Barma, Ceylon, Java \& Srilanka $[5,6]$. This plant recently gained a great therapeutically relevance owing to their high Coumarins and monoterpenoids content, which is explored for treatment of snake bite [7]. Stem bark mainly consists of furan Alkaloid; Coumarins; Flavanones; Lignan; triterpene [8]. It is useful as tonic in diarrhoea, dysentery, stomatitis, tumors, cough, asthma, leucorrhoea, wounds and ulcers. Fruits, leaves and stem bark of $F$. limonia have been studied for anti-tumor [9], larvicidal [10] and antimicrobial activity [8].

Marmesin is one of the most prevalent linear dihydrofuranocoumarin, is abundant in species belonging to the families of Umbelliferae, Apiaceae, Rutaceae, Moraceae, and Leguminoseae $[11,12]$. It is originally isolated from indigenous indian plants, Aegle marmelos Correa [13], and later from the Hawiian shrub Pelea barbigera [14] both of these are from rutaceae family. It has an amazing array of scientifically acknowledged benefits for key areas of health, as dermal photosensitizing activity beneficial in the treatment of leucoderma [15], antifungal activity [16], phytoalexin [17], feeding deterrence effects [18] and radical scavenging activity [19]. Currently HPTLC is often used as an alternative to HPLC for the quantification of plant products because of its simplicity, accuracy, cost-effectiveness and rapidity [20]. The present study is based on development of methods for determination of marmesin by HPTLC in F. limonia stem bark that may contribute in standardization of raw material of the plant and its formulation. 


\section{Experimental}

\subsection{Reagents and Chemicals}

All the chemicals, including solvents, were of analytical grade from E. Merck, India. The HPTLC plates Si $60 \mathrm{~F}_{254}$ $(20 \mathrm{~cm} \times 20 \mathrm{~cm})$ were purchased from E. Merck (Darmstadt, Germany).

\subsection{Plant Materials}

The plant material of Feronia limonia was collected in the months of September- October 2008 from campus of The M.S. University, Vadodara (Gujarat). They were authenticated in the Botany Department and a voucher specimen (No.Pharmacy/FL/ 08-09/01/MJ) has been deposited in the Pharmacy Department of The M. S. University of Baroda, Vadodara, India.

\subsection{Extraction and Isolation of Reference Compound (MR-1) from Feronia Limonia}

Air-dried and finely powdered stem barks of the plant $(500 \mathrm{~g})$ were exhaustively extracted at temperature (60$\left.80^{\circ} \mathrm{C}\right)$ with methanol $(3 \times 1.5 \mathrm{~L})$ in a soxhlet apparatus and the pooled extracts then obtained were concentrated under vacuum to give methanolic extract. Methanolic extract was made hydroalcoholic by addition of hot distilled water in 1:1 ratio partitioned with chloroform (100 $\mathrm{mL} \times 4$ ), and combined chloroform fraction was concentrated in vacuum to afford a brown residue $(4.5 \mathrm{~g})$. This residue was chromatographed over a Silica gel (60\#120 mesh size) column eluting with toluene followed by increasing concentrations of ethyl acetate and methanol. Fraction 9-10 (toluene: ethyl acetate, 60:40) yielded yellowish crystal resulted in mixture of compounds on TLC. Further purification of MR-1 was achieved by preparative TLC (chloroform: methanol, 9.8:0.2) and confirmed by analytical HPLC. MR-1 obtained as white crystal (118 $\mathrm{mg}$ ). The structure elucidation of MR-1 was performed with the help of ${ }^{13} \mathrm{CNMR}$, mass (ESI-MS) spectra and $\mathrm{CHN}$ analysis that confirmed as marmesin reported earlier [2,3-dihydro-2-(1-hydroxy-1 methylethyl)- 7H-furo[3, 2-g][1]benzopyran-7-one] (Figure 1)[21].

Marmesin (MR-1): $\mathrm{C}_{14} \mathrm{H}_{14} \mathrm{O}_{4}$ m.p. $188-190^{\circ}\left(\mathrm{CHCl}_{3}\right.$-petrol); IR spectra: 3479,2977, 2929, 1703, 1630, 1572, 14851444, 1404 and $819 \mathrm{~cm}^{-1} ;{ }^{1} \mathrm{H}$ NMR: $\delta 1.23$ and 1.37( $>\mathrm{CMe}_{2}, 1.85(1 \mathrm{H}$, br), $3.23(2 \mathrm{H}$, br d, J $8.8 \mathrm{~Hz}$, $\left.\mathrm{H}_{2}-1^{\prime}\right), 4.74$ (1H, t, J $\left.8.8 \mathrm{~Hz}, \mathrm{H}-2^{\prime}\right), 6.21(1 \mathrm{H}, \mathrm{d}, J 9.5 \mathrm{~Hz}$, H-3), 6.74(1H, s, H-8), 7.22(1H, s, H-5), 7.59(1H, d, J $9.5 \mathrm{~Hz}, \mathrm{H}-4)$; m/z (\%) $246\left(\mathrm{M}^{+}, 39\right), 213(20), 188$ (75), 187(100), 175(15), 160(30), 131(19), 59(66), 43(7) ; CHO \% elements- (Oxyzen-25.915), (Carbon-67.191) and (Hydrozen-5.480).

\subsection{Preparation of Crude Extract}

Accurately weighed $5 \mathrm{~g}$ of the coarse powder of F. limonia stem barks were extracted with methanol $(3 \times 50 \mathrm{~mL})$ under reflux (30 min each time) on a water bath. The combined extracts were filtered and concentrated, and transferred to a $25 \mathrm{~mL}$ volumetric flask and the volume was made up with methanol.

\subsection{Preparation of Standard Solution}

A stock solution of marmesin $(100 \mu \mathrm{g} \mathrm{mL}-1)$ was prepared by dissolving $1 \mathrm{mg}$ of accurately weighed marmesin in methanol and making up the volume of the solution to $10 \mathrm{~mL}$ with methanol.

\subsection{Chromatography}

A Camag TLC system equipped with Camag Linomat V an automatic TLC sample spotter, Camag glass twin trough chamber $(20 \times 10 \mathrm{~cm})$, Camag scanner 3 and integrated win CATS 4 Software were used for the analysis. TLC was performed on a pre-coated TLC plate silica gel60F 254

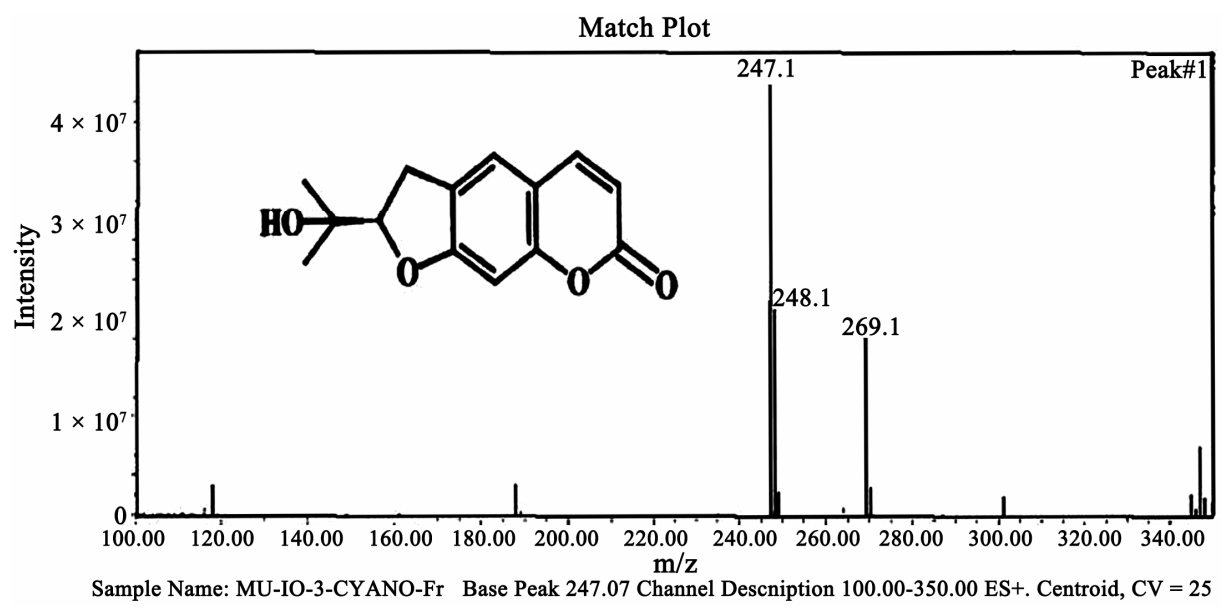

Figure 1. Mass spectroscopy and chemical structure of marmesin. 
$(20 \mathrm{~cm} \times 10 \mathrm{~cm})$. Samples and standards were applied on the plate as $8 \mathrm{~mm}$ wide bands with an automatic TLC sampler (Linomat V) under a flow of $\mathrm{N}_{2}$ gas, $10 \mathrm{~mm}$ from the bottom and $10 \mathrm{~mm}$ from the side and the space between two spots were $15 \mathrm{~mm}$ of the plate. The linear ascending development was carried out in a Camag twin trough chamber $(20 \mathrm{~cm} \times 10 \mathrm{~cm})$ which was presa- turated with $20 \mathrm{~mL}$ mobile phase chloroform: methanol $(9.5: 0.5 \mathrm{v} / \mathrm{v})$ for $20 \mathrm{~min}$ at room temperature $\left(25 \pm 2{ }^{\circ} \mathrm{C}\right.$ and $40 \%$ relative humidity). The length of the chromatogram run was $9 \mathrm{~cm}$. Subsequent to the development, TLC plates were dried under stream of hot air and then subjected to densitometric scanning using a Camag TLC scanner III (Camag, Switzerland) with win CATS software (version 1.4.1) in the absorbance- reflectance scan mode. Quantitative evaluation of the plate was performed in absorption-reflection mode at $338 \mathrm{~nm}$. Quantification of marmesin in the extract of F. Limonia stem barks was performed by external standard method, using pure marmesin as standard.

\subsection{Calibration Curve for Marmesin}

Stock solution of marmesin $(100 \mu \mathrm{g} \mathrm{mL}-1)$ was prepared in methanol and different amounts (20-100 ng spot $\left.{ }^{-1}\right)$ were applied on a TLC plate, using Linomat $\mathrm{V}$ for preparing five point calibration graphs of peak area versus concentration. The regression equation for marmesin was $1089.554+230.603 \mathrm{x}$ and co-relation coefficient $\left(r^{2}\right)$ was 0.999 .

\subsection{Quantification of Marmesin in Test Sample}

Ten microlitres of sample solution were applied in triplicate on a TLC plate and developed, scanned as above. Peak areas were recorded and the amount of marmesin was calculated using the calibration plot.

\subsection{Specificity}

The specificity of the method was ascertained by co-an-

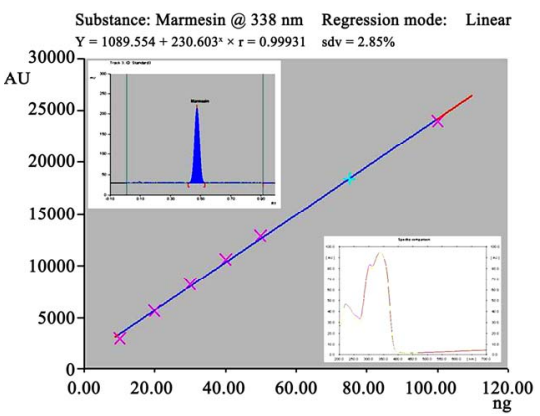

(a) alyzing standard and sample. The band for marmesin in sample was confirmed by comparing the $R f(0.49)$ and absorption spectra of the spot to that of reference compound. The peak purity of marmesin peak in sample track was assessed by comparing the spectra at peak start, peak apex and peak end positions of the band. Good correlation was also obtained between standards and sample overlay spectra $\left(r^{2}>0.99\right)$.

\subsection{Method Validation}

The method was validated for precision, accuracy and repeatability [22]. Instrumental precision was checked by repeated scanning of the same spot 20 and $100 \mathrm{ng}$ five times and was expressed as coefficient of variance (\% RSD). Method precision was studied by analyzing the standards 20 and $100 \mathrm{ng}$ per spot under the same analytical procedure and lab conditions on the same day and on different days (inter-day precision) and the results were expressed as \% RSD. Accuracy of the method was tested by performing the recovery studies of the pre-analysed sample with standard at three levels (55.02, 68.78 and $\left.82.53 \mu \mathrm{g} \mathrm{mL}^{-1}\right), \%$ recovery and average \% recovery were calculated.

\section{Result and Discussion}

Chloroform: methanol $(9.5: 0.5 \mathrm{v} / \mathrm{v})$ gave the best resolution and satisfactory separation of the components in the extracts with well resolved peaks. A total of nine peaks were observed methanol extracts of samples. A comparative chromatographic display is shown in Figures 2(a) \& 2(b). The densitometric scanning was therefore performed at a wavelength of $338 \mathrm{~nm}$. The identities of the bands of marmesin $(R f=0.49)$, in the sample extract were confirmed by overlaying their absorption spectra with those of the standard compounds using the TLC Scanner 3. The peak purity of the separated marmesin was confirmed by recording the absorption spectra at start to middle and middle to the end of the peak.

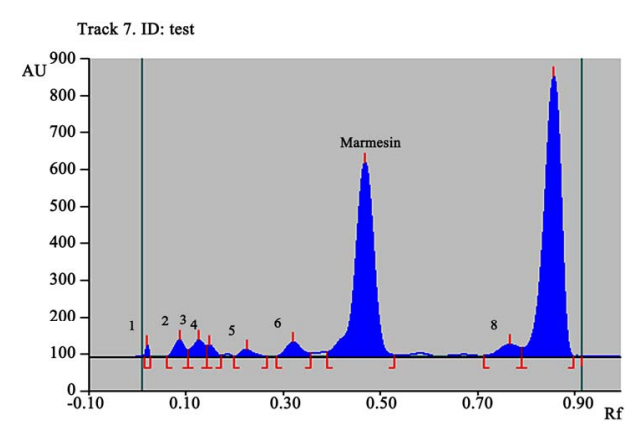

(b)

Figure 2. (a) TLC chromatogram, for a standard marmesin in methanol, Calibration curve and Three-dimensional overlaid chromatogram of standard track and sample track for marmesin; (b) TLC chromatogram, for stem barks methanolic extract of Feronia Limonia. 


\subsection{System Suitability Test}

\subsubsection{Linearity and Detection Limit}

Linearity was checked by applying standard solutions of marmesin at five different concentration levels. The calibration curve was drawn in the concentration range of 20-100 ng $\operatorname{spot}^{-1}$ (Figures 2(a) and 2(b)). The equation for the calibration curve of marmesin is $\mathrm{Y}=1089.554+$ $230.603 \mathrm{x}$ and the correlation coefficient of the calibration plot was 0.999 indicating good linearity. Results of regression analysis on the calibration curve and detection limits are presented in Table 1(a).

\subsubsection{Precision Studies}

Instrumental precision was checked by repeated scanning of the same spots ( 20 and $100 \mathrm{ng} \mathrm{spot}^{-1}$ ) of standard marmesin five times and the RSD values were 1.56 and 1.82 for 20 and $100 \mathrm{ng} \mathrm{spot}^{-1}$, respectively. To determine the precision of the developed assay method 20 and $100 \mathrm{ng}$ spot $^{-1}$ of the marmesin standard was analysed five times within the same day to determine the intra-day variability. The RSD values were 3.41 and 6.29 for 20 and $100 \mathrm{ng}$

Table 1. Method validation parameters for quantification of marmesin using proposed TLC densitometric method.

(a) Linearity regression data

\begin{tabular}{cll}
\hline S1 no. & \multicolumn{1}{c}{ Parameter } & \multicolumn{1}{c}{ Results } \\
\hline 1 & RF & 0.49 \\
2 & Dynamic range $\left(\right.$ ng spot $\left.^{-1}\right)$ & $20-100$ \\
3 & Equation & $\mathrm{Y}=1089.554+230.603 \mathrm{x}$ \\
4 & Slope & 230.603 \\
5 & Intercept & 1089.554 \\
6 & Limit of detection & $5 \mathrm{ng}$ \\
7 & Limit of quantification & $15.15 \mathrm{ng}$ \\
8 & Linearity (correlation coefficient) & 0.999 \\
9 & Specificity & Specific \\
\hline
\end{tabular}

(b) Precision studies data

\begin{tabular}{cccc}
\hline \multirow{2}{*}{$\begin{array}{c}\text { Concentration } \\
\left(\text { (n spot }^{-1}\right)\end{array}$} & $\begin{array}{c}\text { Instrumental precision } \\
(\% \text { RSD })\end{array}$ & \multicolumn{2}{c}{ Method precision (\% RSD) } \\
\cline { 3 - 4 } & 1.56 & Intra-day & Inter-day \\
\hline 20 & 1.82 & 3.41 & 2.68 \\
100 & 6.29 & 2.83 \\
\hline
\end{tabular}

(c) Recovery studies of marmesin

\begin{tabular}{ccccc}
\hline S1 no. & $\begin{array}{c}\text { Amount of marmesin } \\
\text { present in the sample } \\
(\mu \mathrm{g})\end{array}$ & $\begin{array}{c}\text { Amount } \\
\text { added } \\
(\mu \mathrm{g})\end{array}$ & $\begin{array}{c}\text { Amount } \\
\text { found } \\
(\mu \mathrm{g})\end{array}$ & $\begin{array}{c}\text { Avg. } \\
\text { Recovery } \\
(\%)\end{array}$ \\
\hline 1 & 68.78 & 55.02 & 122.11 & 98.83 \\
2 & 68.78 & 68.78 & 136.92 & \\
3 & 68.78 & 82.53 & 148.81 & \\
\hline
\end{tabular}

spot $^{-1}$, respectively. Similarly the inter-day precision was tested on the same concentration levels on 2 days and the RSD values were 2.68 and 2.83, respectively (Table 1(b)).

\subsubsection{Sample Analysis and Recovery Studies}

This developed TLC method was subsequently applied for the analysis of marmesin in the methanolic extract of Feronia limonia stem barks. The marmesin content of the stem barks by this proposed method was found to be $0.03412 \%$. For the examination of recovery rates, 80 , 100 and $120 \%$ of pure marmesin were added to preanalyzed sample and quantitative analysis was performed. The average recovery was 98.83 (Table 1(c)).

\section{Conclusions}

Thin layer chromatography is a globally accepted, rational and practical solution to characterize the crude plant drug along with pharmacologically active constituent enriched standardized extracts and their formulations. TLC method on silica gel $60 \mathrm{~F}_{254}$ with chloroform-methanol $(9.5: 0.5, \mathrm{v} / \mathrm{v})$ was developed and densitometric evaluation was performed at $338 \mathrm{~nm}$. This method is simple, specific, precise, accurate and robust for the determination of marmesin [2,3-dihydro-2-(1-hydroxy-1 methylethyl)$7 \mathrm{H}$-furo[3,2-g][1]benzopyran-7-one]. This standardized TLC procedure may be used effectively for the screening analysis as well as quality evaluation of the plant or its derived herbal products.

\section{REFERENCES}

[1] N. Govindarajan, M. Vijayakumar, M. Thakur, V. K. Dixit, S. Mehrotra and P. Pushpangadan, "Standardization and Determination of Antioxidant Activity of Chlorophytum Borivilianum," Journal of natural Products, Vol. 11, October 2005, pp. 165-169.

[2] M. Thakur, S. Bhargava and V. K. Dixit, "Immunomodulatory Activity of Chlorophytum borivilianum Sant. \& F," Evidence-based Complementary and Alternative Medicine, Vol. 4, No. 4, 2007, pp. 419-423.

[3] S. K. Chauhan, B. P. Singh and S. Agrawal, "Determination of Pistacienoic Acids in Pistacla Integerrima Stewart Ex Brandis by HPTLC and HPLC," Indian Journal of Pharmaceutical Science, Vol. 64, February 2002, pp. 403-405.

[4] D. L. Dreyer, M. V. Pickering and P. Cohan, "Distribution of Limonoids in the Rutaceae," Phytochemistry, Vol. 11, No. 2, February 1972, pp.705-713.

[5] J. D. Hooker, "The Flora of British India," L. Reeve \& Co, London, Vol. 1, No. 1, 1875, p.178.

[6] K. R. Kirtikar, B. D. Basu and I. C. S. An, "Indian Medicinal Plants," Bishen Singh Mahendra Pal Sigh, India, Vol. 1, 1933, pp. 496-498.

[7] A. Agarwal, I. R. Siddique and J. Singh, "Coumarins from the Roots of Feronia limonia," Phytochemistry, Vol. 
28, No. 4, 1989, pp.1229-1231.

[8] M. M. Rahman and I. G. Alexander, "Antimicrobial Constituents from the Stem Bark of Feronia Limonia," Phytochemistry, Vol. 59, No. 1, January 2002, pp.73-77.

[9] Y. Saima, A. K. Das, K. K. Sarkar, A. K. Sen and P. Sur, "An Antitumor Pectic Polysaccharide from Feronia limonia," International Journal of Biological Macromolecules, Vol. 27, No. 5, August 2000, pp.333-335.

[10] A. A. Rahuman, G. Gopalakrishnan, B. S. Ghouse, S. Arumugam and B. Himalayan, "Effect of Feronia Limonia on Mosquito Larvae," Fitoterepia, Vol. 71, No. 5, September 2000, pp. 553-555.

[11] S. A. Brown, "Biochemistry of the Coumarins. In Recent Advances in Phytochemistry," In: T. Swain, J. B. Harborne and. C. F. Van Sumere, Ed., Plenum Press, New York, Vol. 12, 1978, pp. 249-286.

[12] H. G. Floss, "Biosynthesis of Furanocoumarins. In Recent Advances in Phytochemistry," Proceedings of the 9th Annual Symposium of the Phytochemical Society of North America, V. C. Runeckles and J. E. Watkins, Ed., Appelton-Century-Crofts, New York, Vol. 4, 1972, pp. 143-164.

[13] A. Chatterjee and S. S. Mitra, "On the Constitution of the Active Principles Isolated from the Matured Bark of Aegle marmelos Correa," Journal of the American Chemical Society, Vol. 71, February 1949, p.606.

[14] T. Higa and P. J. Scheuer, "Coumarins and Flavones from Pelea Barbigera (Gray) Hillebrand (Rutaceae)," Journal of the Chemical Society-Perkin Transactions, Vol. 1, 1974, pp. 1350-1352.

[15] T. O. Soine, "Naturally Occurring Coumarins \& Related Physiological Activities," Journal of Pharmaceutical Sciences, Vol. 3, No. 53, 1964, pp. 231-262.
[16] U. Afek, S. Carmeli and N. Aharoni, "The Involvement of Marmesin in Celery Resistance to Pathogens during Storage and the Effect of Temperatures on its Concentration," Phytopathology, Vol. 85, 1995, pp.1033-1036.

[17] U. Afek, J. Orenstein and N. Aharoni, "The Involvement of Marmesin and Its Interactionwith GA3 and Psoralens in Parsley Decay Resistance," The Canadian Journal of Plant Pathology, Vol. 24, 2002, pp. 61-64.

[18] T. T. John and G. M. Jocelyn, "Biological Activity of Marmesin and Demethylsuberosin against a Generalist Herbivore, Spodoptera exigua (Lepidoptera: Noctuidae)," Journal of Agricultural and Food Chemistry, Vol. 44, 1996, pp. 2859-2864.

[19] V. Vimal and T. Devaki, "Linear Furanocoumarin Protects Rat Myocardium against Lipid Peroxidation and Membrane Damage during Experimental Myocardial Injury," Biomedicine \& Pharmacotherapy, Vol. 58, No. 6-7, 2004, pp. 393-400.

[20] K. Arvind, R. K. Tripathi, A. K. Verma, M. M. Gupta and P. S. K. Suman, "Quantitative Determination of Phyllanthin and Hypophyllanthin in Phyllanthus Species by High- Performance Thin Layer Chromatography," Phytochemical Analysis, Vol. 17, No. 6, 2006, pp. 394-397.

[21] A. Patra, S. K. Mishra and S. K. Chaudhuri, "Constituents of Limonia Acidissima: Applications of Two-Dimensional NMR Spectroscopy in Structural Elucidation," Journal of the Indian Chemical Society, Vol. IXV, 1988, pp. 205-208.

[22] ICH guideline Q2R1, validation of analytical procedures: text and methodology (November 1996/2005) Geneva, Switzerland. 